\title{
Regime tecnológico e ambiente de inovação para 0 setor de serviços de telecomunicação brasileiro
}

\author{
Adriano Alves de Rezende* \\ Silvia Harumi Toyoshima**
}

Recebido: 03/10/2012 Versão Revisada (entregue): 11/07/2013 Aprovado: 30/07/2013

\begin{abstract}
Resumo
Este artigo analisa o desenvolvimento do setor de serviços de telecomunicação brasileiro à luz da teoria evolucionária neoschumpeteriana. Buscou-se verificar se as características do regime tecnológico brasileiro adequam-se às do cenário internacional, mapear o ambiente de inovação onde os serviços de telecomunicação se inserem e analisar se o Estado, pós-privatização do setor, fomentou a construção de um regime tecnológico e de um ambiente de inovação capazes de promover o desenvolvimento brasileiro. A pesquisa desenvolveu-se mediante análise documental e de dados das Pesquisas de Inovação Tecnológica (2005 e 2008). O regime tecnológico foi estabelecido segundo a taxonomia de Marsili (2001). Concluiu-se que o regime tecnológico dos serviços de telecomunicação brasileiros possui similaridades com o padrão norte-americano e que o setor tende a ser supplier dominated. O ambiente de inovação demonstrou que a estrutura legal-organizacional específica para os serviços de telecomunicação não acompanha o dinamismo inovativo do setor. Já a estrutura que não é específica para sistemas de telecomunicação é que fomenta o ambiente de inovação.
\end{abstract}

\footnotetext{
Professor do Departamento de Ciências Econômicas da Universidade Estadual de Santa Cruz (UESC), Ilhéus (BA), Brasil. E-mail: adriano.rezende01@gmail.com

** Professora do Departamento de Ciências Econômicas da Universidade Federal de Viçosa (UFV), Viçosa (MG), Brasil. E-mail: htsilva@ufv.br
} 
Palavras-Chave | Telecomunicações; Ambiente de Inovação; Regime Tecnológico; Teoria Evolucionária Neoschumpeteriana

Códigos JEL | N76; O14; O31; O33; O38

\title{
Technological regime and Innovation Environment for Brazilian telecommunication sector services
}

\begin{abstract}
This paper analyzes the development of the Brazilian telecommunication services sector in the neo-Schumpeterian Evolutionary Theory perspective. We sought to determine whether the Brazilian technological regime characteristics fits into the international scene; to map the innovation environment in which telecommunication services operate; and to consider whether the state post-privatization of the sector encouraged the construction of a technological regime and innovation environment capable of promoting the development of Brazil. The research was developed based on documental analysis and on the Technological Innovation Research (PINTEC) data for 2005 and 2008. The technological regime was established according to Marsili's (2001) taxonomy. The paper concludes that the technological regime of Brazilian telecommunication services has similarities with the U.S. standard and tends to be a supplier dominated sector. The innovation environment showed that the legal-organizational structure specific to the telecommunication services sector does not accompany the innovative dynamism of the sector. The structure that is not specific to telecommunication services sector foster an innovation environment.
\end{abstract}

KEYWORDS | Telecommunications; Innovation Environment; Technological Regime; NeoSchumpeterian Evolutionary Theory

JEL-CODES | N76; O14; O31; O33; O38 
Regime tecnológico e ambiente de inovação para o setor de serviços de telecomunicação

\section{Introdução}

O objetivo deste artigo é discutir o desenvolvimento do setor de serviços de telecomunicações (STs) brasileiro à luz da teoria evolucionária neoschumpeteriana. Especificamente, procurou-se, para os STs brasileiros: verificar se suas características se adéquam às do regime tecnológico (RT) traçado no cenário internacional; construir um quadro do seu ambiente de inovação (AI); e analisar se houve, por parte do Estado, após a privatização dos STs em 1995, fomento para a construção de um RT e AI sólidos, capazes de promover o desenvolvimento da economia brasileira.

A partir da quebra do monopólio estatal das telecomunicaçôes, por meio da Emenda Constitucional n. 08/95, a Lei Geral de Telecomunicações - LGT (Lei n. 9.472/97) constituiu-se no marco regulatório do setor para abertura da concorrência nos STs brasileiros. Esse modelo consolidou-se com a privatização do Sistema Telebrás e Embratel, que criou um ambiente mais competitivo e alterou o papel do Estado, de provedor para regulador (FREITAS, 2002). A LGT ainda normatizou a reestruturação do setor e criou, em 1997, a Agência Nacional de Telecomunicações - Anatel - como órgão regulador independente. Posteriormente, os Decretos n. ${ }^{\circ}$ 2.534/98 e 6.654/08 instituíram, respectivamente, a primeira e a segunda versão do Plano Geral de Outorgas (PGO), definindo as formas de atuação dos agentes nesse mercado.

O mercado de telecomunicações brasileiro tem grande representatividade no setor de serviços. Caracterizada por ser intensiva em capital e composta por empresas de grande porte, a atividade de STs foi responsável por $60,1 \%$ da receita operacional líquida do setor de serviços de informação e comunicação, com faturamento de R \$ 122,2 bilhôes, segundo a Pesquisa Anual de Serviços (IBGE, 2008). Classificados como um setor baseado em ciência, segundo as taxonomias de Pavitt (1984) e Marsili (2001), estes serviços apresentam uma dinâmica inovativa intensa, que varia conforme as condiçóes oferecidas pelo mercado, determinadas a partir da natureza do RT e dos determinantes do AI no qual o setor se insere.

Alguns trabalhos que trataram das atividades dos STs no Brasil foram utilizados nesta pesquisa, mesmo apresentando abordagens distintas, uma vez que tais pesquisas são relativamente escassas. Galina e Plonski (2000, 2005), por exemplo, verificaram que as empresas que desenvolvem produtos e equipamentos para os STs são subsidiárias de organizações transnacionais e associam seus investimentos em P\&D a incentivos fiscais, principalmente os constantes na Lei de Informática. Dutra (2007) discutiu a inovação nas telecomunicações brasileiras e constatou que 
as operadoras realizam basicamente inovações incrementais. Já Santa Rita e Sbragia (2006) observaram que as inovações não são totalmente correlacionadas com a competitividade no setor de telefonia móvel (SMP) no Brasil.

A análise da evolução do setor de telecomunicações mundial sob uma ótica evolucionária pode ser encontrada em dois trabalhos de Fransman (2003, 2007), que, no primeiro, estuda os principais eventos que moldaram o SMP e, no segundo, analisa as relações existentes entre os players do setor de telecomunicações, designando-as como Novo Ecossistema das TICs. Já Prieger (2002) aborda o efeito da regulação do mercado de telecomunicações norte-americano sobre o processo inovativo e o fornecimento de serviços. $\mathrm{O}$ autor conclui que maior regulamentação do setor inibe a criação de empresas e de serviços inovadores no mercado.

Diante do exposto, acredita-se que a contribuição do artigo com a construção e avaliação do RT e do AI dos STs brasileiro, a partir de pesquisas (Pintec) e das legislaçôes dos STs, é importante para subsidiar o aprimoramento da política inovativa para esse setor.

A seguir, são apresentados os conceitos de RT e AI sob a perspectiva evolucionária neoschumpeteriana e discutidas as inovações em serviços. A terceira seção trata da metodologia da pesquisa e a quarta mostra os resultados do trabalho. Por fim, são realizadas as considerações finais.

\section{Um olhar evolucionário sobre o setor de serviços}

Nessa seção são expostos os conceitos evolucionários de Regimes Tecnológicos (RT) e Ambiente de Inovação (AI). Em seguida, é apresentada a taxonomia de Marsili (2001) sobre cinco tipos de RTs, a qual não se contrapõe à de Pavitt (1984) ou à de Malerba e Orsenigo (1993), mas estende a compreensão das características dos processos inovativos importantes para distinguir os RTs. Segundo Guidolin e Martinelli (2008), a taxonomia de Marsili (2001) se adéqua melhor à realidade do setor de serviços porque distingue a intensidade de inovação empregada em cada serviço e possibilita destacar as peculiaridades do mercado brasileiro. No caso deste trabalho, ela permite um melhor entendimento dos diversos serviços de telecomunicações. ${ }^{1}$

1 Outra possibilidade seria a de utilizar o modelo de taxonomia proposto por Tidd et al. (2001), que inclui empresas intensivas em inovação. Contudo, os estudos sobre inovação em serviços destacam que há mais diversidade de configuraçôes dentro do setor do que o previsto nesse modelo (MILES, 1993; MIOZZO; SOETE, 2001). 
Regime tecnológico e ambiente de inovação para o setor de serviços de telecomunicação

\subsection{Regimes tecnológicos (RTs)}

Não existe consenso sobre a definição de regime tecnológico. Contudo, um conceito bastante aceito é de que se trata de uma combinação singular de condiçôes de: oportunidade - capacidade de um setor originar novas tecnologias; apropriabilidade - capacidade de as empresas protegerem suas inovações utilizando mecanismos legais ou gerenciais; cumulatividade - trajetória de construção do conhecimento, seja pessoal, tecnológico, organizacional ou da empresa; e base de conhecimento caráter tácito e específico da tecnologia, ou seja, aquele que não pode ser codificado, sendo compartilhado por colaboradores e colegas que tenham experiências em comum (MALERBA; ORSENIGO, 1993). Assim, a tecnologia não é um bem livre, mas apresenta características que a diferencia de outra, gerando maior, ou menor, dinamismo nas economias (DOSI, 1988a, 1988b). Na atual fase do capitalismo, as tecnologias de informação e comunicação (TICs) constituem-se como as mais dinâmicas, o que inclui o setor de STs. Maior dinamismo significa, por sua vez, que a atividade inovativa deve ser mantida num nível alto.

A inovação, de acordo com a abordagem evolucionária, é permeada por muita incerteza, o que leva as empresas a adotarem regras estáveis para tentar minimizá-la, desenvolvendo competências de caráter local e específico, de natureza tácita, que são armazenadas como rotinas e norteiam o comportamento da empresa. As rotinas referentes à inovação das firmas estão fortemente vinculadas às características do RT em que estas operam (DOSI, 1988a).

Dessa forma, as empresas necessitam de estratégias tecnológicas que dependem, segundo Nelson e Winter (1982), de três fatores primordiais: path dependency ou trajetória, em que as escolhas feitas no passado, ou seja, as rotinas anteriores, acabam determinando o comportamento da empresa no presente e no futuro; ativos complementares, que podem ser entendidos como serviços pós-venda, capacitação de pessoal nas atividades consideradas estratégicas, etc.; e oportunidade tecnológica, que consiste na facilidade de gerar inovação mediante o aporte de qualquer montante de recursos para a pesquisa.

\subsection{A taxonomia de Orietta Marsili}

Marsili (2001) desenvolveu uma tipologia, com base em indicadores dos países economicamente desenvolvidos, ${ }^{2}$ que identifica cinco regimes tecnológicos (Qua-

2 Dados primários sobre patentes dos Estados Unidos e informaçōes das maiores empresas mundiais no Science and Technology Policy Research (STPR) (MARSILI, 2001, p. 1). 
dro 1): baseado em ciência; processos fundamentais ou básicos; sistemas complexos de conhecimento; engenharia de produto; e processos contínuos. Cada um deles possui características específicas dos processos inovativos, tais como: oportunidade tecnológica; ${ }^{3}$ barreiras tecnológicas à entrada - em conhecimento ou em escala; persistência da inovação; diversidade tecnológica interfirmas; diferenciação das bases de conhecimento; fontes externas de conhecimento; ligaçôes com a pesquisa acadêmica; e natureza da inovação.

Guidolin e Martinelli (2008) verificaram que esta tipologia, mesmo sendo inicialmente desenhada para a indústria de manufatura, é adaptável aos serviços, pois ainda não há algo similar e de senso comum desenvolvido para este setor. Gallouj e Windrum (2009) e Tether (2004) citam esta abordagem como de assimilação ou demarcação. Contudo, segundo Gallouj e Windrum (2009), o objetivo desta abordagem de síntese não é apenas transpor os conceitos de inovação em manufatura para serviço, mas também desenvolver um conceito integrado, que seja aplicável a ambos, e que abarque todos os aspectos da atividade inovadora.

\subsection{0 ambiente de inovação (Al)}

Neste estudo, a definição de AI adotada será a da Rede de Tecnologia \& Inovação do Rio de Janeiro (Redetec), também compatível com o método de determinação de AI proposto por Malachias e Meirelles (2009).

A Redetec (2008) define AI como uma composição entre espaço de conhecimento, onde recursos humanos qualificados e novos conhecimentos são gerados de forma constante, e espaço de consenso, onde são criadas ideias e estratégias para dinamização do processo de inovação. De acordo com a Rede, para a consolidação de um sistema de inovação dinâmico e, consequentemente, de um AI, existem algumas competências essenciais, entre as quais destacam-se: existência de universidades com atividades de ensino e pesquisa; programas de pós-graduação stricto sensu com nível de excelência; formação de mão de obra qualificada em áreas estratégicas para inovação; e publicações científicas com alto nível de qualidade nas áreas estratégicas para inovação (REDETEC, 2008, p. 160).

A literatura evolucionária enfatiza que o processo de aprendizado pode ser interno e externo à empresa. Segundo Dosi (1988b), geralmente, o interno vincula-se às principais funções da empresa (marketing, produção, P\&D e organização), podendo

3 Fontes de oportunidades tecnológicas são o quanto setores e empresas divergem em termos de aprendizado a partir da produçāo, uso, interação, utilização de fontes externas de C\&T, ampliando as possibilidades de inserçáo de outras tecnologias. 
QUADRO 1

Regimes tecnológicos no sistema industrial

\begin{tabular}{|c|c|c|c|c|c|c|c|c|c|}
\hline $\begin{array}{c}\text { Regimes } \\
\text { tecnológicos } \\
\text { (RTs) }\end{array}$ & $\begin{array}{c}\text { Oportu- } \\
\text { nidade } \\
\text { tecnológica }\end{array}$ & $\begin{array}{c}\text { Barreiras } \\
\text { tecnológicas } \\
\text { à entrada em } \\
\text { conhecimento/ } \\
\text { escala }\end{array}$ & $\begin{array}{c}\text { Persistência } \\
\text { da } \\
\text { inovaçáo }\end{array}$ & $\begin{array}{c}\text { Diversidade } \\
\text { entre } \\
\text { empresas }\end{array}$ & $\begin{array}{c}\text { Diferenciaçáo } \\
\text { das bases de } \\
\text { conhecimento } \\
\text { (principais } \\
\text { direçôes) }\end{array}$ & $\begin{array}{c}\text { Fontes } \\
\text { externas de } \\
\text { conhecimento }\end{array}$ & $\begin{array}{l}\text { Ligaçōes com a } \\
\text { pesquisa } \\
\text { acadêmica } \\
\text { (campos de } \\
\text { conhecimento) }\end{array}$ & $\begin{array}{c}\text { Natureza } \\
\text { da } \\
\text { inovaçáo }\end{array}$ & $\begin{array}{c}\begin{array}{c}\text { Setores } \\
\text { industriais }\end{array} \\
\text {. }\end{array}$ \\
\hline $\begin{array}{l}\text { Processos } \\
\text { básicos }\end{array}$ & Média & Alta (escala) & Alta & Média & $\begin{array}{l}\text { Baixa (horizontal e } \\
\text { à montante) }\end{array}$ & $\begin{array}{l}\text { Empresas } \\
\text { subsidiárias e } \\
\text { usuários }\end{array}$ & $\begin{array}{l}\text { Muito importante e } \\
\text { direta (ciência básica } \\
\text { aplicada) }\end{array}$ & Processo & $\begin{array}{l}\text { Química, mineração e } \\
\text { petróleo }\end{array}$ \\
\hline $\begin{array}{l}\text { Sistemas } \\
\text { complexos }\end{array}$ & Média & Média/alta & $\begin{array}{l}\text { Alta em } \\
\text { tecnologia, mas } \\
\text { não em produtos }\end{array}$ & Média & Alta (à montante) & $\begin{array}{l}\text { Sistema } \\
\text { complexo de } \\
\text { fontes }\end{array}$ & $\begin{array}{l}\text { Muito importante } \\
\text { mas indireta } \\
\text { (engenharia) }\end{array}$ & Produto & $\begin{array}{l}\text { Veículos automotores, } \\
\text { Aeronáutica }\end{array}$ \\
\hline $\begin{array}{l}\text { Engenharia } \\
\text { de Produto }\end{array}$ & Média-alta & Baixa & Média-baixa & Alta & $\begin{array}{l}\text { Alta (horizontal e } \\
\text { à jusante) }\end{array}$ & Usuários & $\begin{array}{l}\text { Não muito } \\
\text { importante } \\
\text { (engenharia } \\
\text { mecânica pervasiva) }\end{array}$ & Produto & $\begin{array}{l}\text { Máquinas nấo } \\
\text { elétricas instrumentos } \\
\text { (controles de máquinas, } \\
\text { instrumentos mecânicos } \\
\text { e eléricos), produtos } \\
\text { fabricados de metal, } \\
\text { produtos de borracha e } \\
\text { plástico }\end{array}$ \\
\hline $\begin{array}{l}\text { Processos } \\
\text { contínuos }\end{array}$ & Baixa & Baixa & $\begin{array}{l}\text { Alta em } \\
\text { metalurgia, mas } \\
\text { não em produtos } \\
\text { (i.e. metais) e } \\
\text { em materiais de } \\
\text { construçāo. } \\
\text { Baixa em outros }\end{array}$ & Alta & $\begin{array}{l}\text { Alta (à montante) } \\
\text { Baixa em } \\
\text { alimentos, bebidas } \\
\text { (à montante } \\
\text { horizontal) }\end{array}$ & $\begin{array}{l}\text { Fornecedores } \\
\text { incorporados } \\
\text { no capital }\end{array}$ & $\begin{array}{l}\text { Não muito } \\
\text { importante (ciência } \\
\text { aplicada pervasiva } \\
\text { i.e. metalurgia e } \\
\text { materiais) } \\
\text { Mais importante e } \\
\text { direta em alimentos } \\
\text { (ciência básica) }\end{array}$ & Processo & $\begin{array}{l}\text { Outras manufaturas, } \\
\text { processos metalúrgicos } \\
\text { (metais básicos, materiais } \\
\text { de construçâ), processos } \\
\text { químicos (têxteis, papel } \\
\text { e madeira), alimentos } \\
\text { e bebidas (alimentos, } \\
\text { bebidas e tabaco) }\end{array}$ \\
\hline
\end{tabular}


decorrer de rotinas, como a ação de produzir (learning-by-doing) e a utilização de máquinas e equipamentos (learning-by-using), ou da busca de melhoria contínua e/ou da criação de novos produtos ou processos produtivos (learning-by-searching). Já o externo refere-se à aquisição de soluções tecnológicas de terceiros, treinamento externo, interação com parceiros comerciais, joint ventures, etc.

Além da empresa, o AI compreende outros agentes, instituições, leis (objeto deste estudo) e ações desenvolvidas que não estão diretamente relacionadas ao RT. Assim, pode-se entender que o AI é tudo aquilo que direta ou indiretamente influencia as atividades inovativas.

Desta maneira, a conjunção dos aspectos do RT, bem como do AI, que, em último caso, também reflete o sistema setorial de inovação, tendem a explicar o perfil inovativo das empresas (MALACHIAS; MEIRELLES, 2009). A identificação do AI decorrerá da observação das variáveis dispostas no Quadro 2, adaptado de Malachias e Meirelles (2009), utilizando os dados da Pintec de 2005 e 2008.

QUADRO 2

Proxies para determinação do ambiente de inovação

\begin{tabular}{|l|l|}
\hline \multicolumn{1}{|c|}{ Proxies } & \multicolumn{1}{c|}{ Definição ou Características } \\
\hline P\&D interno & $\begin{array}{l}\text { Montante investido em P\&D e pessoal destinado de forma fixa ou } \\
\text { ocasional para realização de P\&D. }\end{array}$ \\
\hline $\begin{array}{l}\text { Fontes externas } \\
\text { de P\&D }\end{array}$ & $\begin{array}{l}\text { Absorção, aquisição ou apenas transferência de tecnologias via parceria } \\
\text { com universidade, institutos de pesquisa e centros de referência }(a \\
\text { análise será fundamentada no amparo legal que favoreça a formação } \\
\text { de parcerias). }\end{array}$ \\
\hline Cooperação & $\begin{array}{l}\text { Joint ventures ou outros tipos de parcerias estratégicas entre empresas } \\
\text { para geração de conhecimento. }\end{array}$ \\
\hline $\begin{array}{l}\text { Fomento do setor } \\
\text { público }\end{array}$ & $\begin{array}{l}\text { Disponibilidade de recursos financeiros governamentais para } \\
\text { investimento em P\&D. }\end{array}$ \\
\hline Educação & $\begin{array}{l}\text { Capacidade de formação de pessoal qualificado com elevado nível de } \\
\text { conhecimento. }\end{array}$ \\
\hline Outras instituiçóes & $\begin{array}{l}\text { Outros tipos de parcerias estratégicas, com outras instituições geradoras } \\
\text { de conhecimento, que não as anteriormente citadas para fontes externas } \\
\text { de P\&D e cooperação. }\end{array}$ \\
\hline Intensidade de P\&D & Frequência e volume de recursos gastos na realização de pesquisas. \\
\hline Treinamento & $\begin{array}{l}\text { Frequência com que cursos de aperfeiçoamento e/ou reciclagem são } \\
\text { realizados pelas empresas. }\end{array}$ \\
\hline
\end{tabular}

Fonte: Adaptado de Malachias e Meirelles (2009). 
Regime tecnológico e ambiente de inovação para o setor de serviços de telecomunicação

\subsection{Inovação em serviços}

O setor de serviços vem ampliando sua participação na geração de empregos e na agregação de valor. Para Kubota (2006), apesar de se tratar de um setor inovativo e dinâmico, muitas vezes apresenta caráter menos tecnológico se comparado com a indústria. Contudo, pouco conhecimento científico foi incorporado sobre o processo de inovação em serviços (MENOR; ROTH, 2007 apud DROEGE et al., 2009).

Como o setor de serviços é mais heterogêneo do que a indústria e o comércio, cada serviço distingue-se dos demais por meio da intensidade de conhecimento empregado e das inovações implementadas (SILVA et al., 2006). Essa inovação é largamente dependente da adoção de tecnologias desenvolvidas externamente, que facilitam a prestação de novos serviços e/ou aumentam a produtividade do serviço (PAVITT, 1984). Para Tether (2004), fabricantes e alguns prestadores de "serviços peculiares", tais como de informática e de telecomunicações, são a fonte dessas novas tecnologias. A grande maioria das tecnologias adotadas é padrão ou tecnologia "off-the-shelf, que são amplamente disponíveis. Há pouca criatividade na utilização de tecnologia nos serviços. Consequentemente, a competição é mais baseada no preço.

De acordo com Gadrey, Gallouj e Wheinstein (1995, p. 14, tradução nossa):

[...] A distinção tradicionalmente feita entre empresa industrial e empresa de serviços tende a perder o seu significado em determinadas situaçôes. Uma série de empresas de alta tecnologia são simultaneamente produtoras de bens de capital, bem como de alta tecnologia em serviços: exemplos deste caso são os principais fabricantes de equipamentos de computação e das telecomunicaçōes. Empresas pertencentes a setores tradicionais como têxteis, por exemplo, agora podem ser qualificadas como empresas de serviços - Benetton, sua principal atividade tornou-se a gestão da informação (marketing de vendas) e as inovaçôes de que são essencialmente orientadas a serviços, este é o ponto neste caso.

Uma peculiaridade da inovação em serviços é que esta ocorre, comumente, em processos e não em produtos (MALACHIAS; MEIRELLES, 2009). Por ser o serviço um processo decorrente da realização do trabalho, a inovação no setor ocorre de maneira mais intensa via aquisição de conhecimento por fontes externas do que por investimentos em P\&D (MEIRELLES, 2006). Logo, as inovações em serviços distinguem-se principalmente por seu caráter intangível. 


\subsection{Serviços em telecomunicações (STs)}

Segundo a Classificação Nacional de Atividades Econômicas (CNAE), telecomunicação é uma divisão (61) da seção Informação e Comunicação (J). A divisão 61 compreende as atividades de prestação de serviços de telecomunicações e serviços conexos, isto é, as atividades de transmissão, emissão ou recepção de símbolos, caracteres, sinais, escritos, imagens, sons ou informaçôes de qualquer natureza. Caracteriza-se, ainda, por abranger a infraestrutura de telecomunicações que dá suporte a estas atividades, podendo ser baseada em uma única tecnologia ou em uma combinação de tecnologias (por fio, por micro-ondas e por satélite). A transmissão de conteúdo é a principal característica destas atividades, sem envolver as tarefas de criação. Já as operadoras de televisão incluem a transmissão e distribuição da programação dos canais de televisão, seja aberta ou por assinatura (CNAE, 2011).

O entendimento pleno dos STs como definido pela CNAE (2011) só ganhou robustez no Brasil após a década de 1990, quando o setor não comportava mais apenas fornecedores de equipamentos e operadoras. Inseriram-se neste segmento algumas áreas como multimídia, semicondutores, softwares, Internet e comércio eletrônico. O segmento de máquinas e equipamentos de telecomunicações passou a atrair investimentos em $\mathrm{P} \& \mathrm{D}$, que eram anteriormente centrados nas operadoras (GALINA; PLONSKI, 2005, p. 133). No cenário mundial, este fato se deu nos países desenvolvidos a partir de meados dos anos 1980, com o final do monopólio nos STs (FRANSMAN, 2007).

Diversos fatores, após a privatização, acabaram por tornar a cadeia produtiva do setor de telecomunicações brasileira extensa, uma consequência natural da especialização das atividades. Atualmente o setor de telecomunicações compreende diversas subcadeias dentro do próprio setor e capilaridades em outros tantos segmentos. Fransman (2007) define estas relações entre os segmentos como simbióticas, dentro do modelo que denominou de Novo Ecossistema das TICs.

Quando se restringe a análise aos STs, o mesmo ocorre, compreendendo este uma vasta gama de segmentos que envolvem operadoras de telefonia e provedores de acesso à Internet e de conteúdo, além daqueles de softwares, equipamentos e outros aparatos tecnológicos que auxiliam a prestação dos STs. Todos têm crescido no mercado mundial, com exceção da telefonia fixa (IUT, 2011). 
Regime tecnológico e ambiente de inovação para o setor de serviços de telecomunicação

\section{Material e métodos}

Com base nos conceitos adotados neste trabalho para definição do regime tecnológico (RT) do setor de STs brasileiro, buscou-se verificar a existência (ou não) de um ambiente de inovação para pleno desenvolvimento do setor. $\mathrm{O}$ delineamento foi efetuado por meio de estatística descritiva a partir dos dados da Pintec 2005 e 2008, do item telecomunicações, segundo seção 61 da CNAE. Complementarmente, foram observadas as políticas regulatórias e de incentivo ao setor a partir de 1995 até os acontecimentos relevantes mais recentes, além de uma revisão de literatura nacional e internacional a respeito do tema. A utilização apenas destas Pintecs deve-se ao fato de os quesitos abordados em ambas atenderem às necessidades deste trabalho e permitirem estabelecer um comparativo entre elas, sendo que o mesmo não é possível com as edições anteriores a 2005. Isso, de certa maneira, limita o estudo, mas não compromete a análise de curto prazo.

Para definir RT foi utilizada a taxonomia de Marsili (2001), uma vez que esta definição pode ser alcançada mediante análise documental. Utilizou-se o RT para setores baseados em ciência, entre os quais, segundo a taxonomia empregada, está o de telecomunicaçôes. A partir daí buscaram-se subsídios tanto nas Pintecs quanto nos instrumentos políticos regulatórios para comparar a intensidade das oito perspectivas tratadas por Marsili (2001) com as encontradas no setor de STs brasileiro (Quadro 4).

Já para definição de ambiente de inovação, foram trabalhadas as variáveis proxies propostas por Malachias e Meirelles (2009). Contudo, as mesmas informações que fundamentaram a construção do AI também foram utilizadas para embasar a definição do RT (Quadro 3).

Além das Pintecs e da política regulatória do setor, complementou-se a pesquisa com levantamento bibliográfico de trabalhos sobre o tema. Utilizaram-se, também, as informações e dados secundários disponíveis em órgãos do governo, como Anatel, Ministério das Comunicaçôes (MC), Ministério da Ciência e Tecnologia (MCT), Coordenação de Aperfeiçoamento de Pessoal de Nível Superior (Capes), entre outros.

Neste trabalho, em alguns momentos, quando examinadas a legislação pertinente ao setor e a de setores correlatos, como a Lei de Inovação (Lei n. 10.973/04) e a Lei de Incentivos Fiscais à Inovação e à Exportação (Lei n. 11.196/05), foi utilizado o segmento de telefonia para ilustrar as mutações ocorridas em STs, pois as legislações dos serviços de TV por assinatura, TV digital, Internet, radiodifusão 
(que engloba rádio e TV aberta) e radiodifusão comunitária possuem similaridades com a da telefonia.

\section{Resultados e discussão}

Inicialmente procurou-se identificar os objetivos da política do governo em relação ao setor de telecomunicaçōes. Estes objetivos, descritos no parágrafo $2^{\circ}$ da LGT, são: fortalecer o setor, com estímulos ao investimento e à concorrência, garantindo a entrada de novas firmas e equilibrar as relaçôes entre as incumbentes; ${ }^{4}$ proporcionar o acesso a melhores serviços a preços compatíveis a toda a sociedade; alterar o papel do Estado de fornecedor do serviço para regulador; e criar as condiçōes para que o setor contribua para o desenvolvimento do país (BRASIL, 1997).

Para garantir e acompanhar a execução desta polífica foi criada a Anatel, mas, mesmo assim, fez-se necessário que a legislação acompanhasse as rápidas mudanças no mercado de STs, tanto no comportamento dos consumidores quanto nos avanços tecnológicos. O governo federal criou, assim, um novo Plano Geral de Outorga (BRASIL, 2008) em substituição ao de 1998, o que deu nova caracterização aos agentes econômicos envolvidos e modificou parte da redação do antigo plano, no intuito de adequá-lo ao desenvolvimento do setor.

A política do setor de telecomunicaçōes é indiretamente favorecida, também, pela legislação pertinente à informática (Leis n. 8.248/91, 10.176/01 e 11.077/04 que tiveram e têm um período de vigência ${ }^{5}$ predefinido). Esse conjunto de instrumentos legais visa conceder incentivos fiscais via redução de impostos, para fomentar a prática de investimentos em P\&D. São beneficiadas as empresas que investem no desenvolvimento de hardware que constem na lista de produtos a serem incentivados ${ }^{6}$ e que atendam aos requisitos de nacionalização do produto predeterminados no PPB (Processo Produtivo Básico). As empresas que se enquadrarem e desejarem usufruir da lei são obrigadas a investir $4 \%$ do faturamento anual em P\&D, sendo até $2,16 \%$ na própria empresa, decorrente de parcerias com universidades e institutos de pesquisa credenciados pelo MCT. Além disso, existem diversos dispositivos legais que

4 Denominação dada às empresas e/ou consórcios que adquiriram as operadoras estatais do Sistema Telebrás e participavam do mercado em condiçōes privilegiadas se comparadas às novas empresas (entrantes).

5 Atualmente os incentivos ao setor de informática são regulamentados pela Lei n. 11.077/04, que dispõe sobre a capacitação e competitividade do setor de informática e automação e estabelece prazo de usufruto de seus benefícios (até 31 de dezembro de 2014), conforme redação do art. $3^{\circ}$, parágrafo $1^{\circ}$.

6 Vide Decreto n. ${ }^{\circ} 6.405$ de 19 de fevereiro de 2008 e Decreto n. 7.010 de 16 de novembro de 2009, que retificam o Decreto n. ${ }^{\circ} 6.405 / 08$. 
preveem o incentivo à capacitação de pessoal, que é considerado investimento em P\&D. Muitas empresas grandes do setor de telecomunicaçôes usufruem desses benefícios, como Alcatel-Lucent, Motorola, ${ }^{7}$ Nokia, Siemens, NEC Solutions, Ericsson. ${ }^{8}$

O Quadro 3, construído a partir do estudo do arcabouço legal-institucional, apresenta as características do setor no Brasil que, de maneira direta ou indireta, dão suporte a um AI.

QUADRO 3

Insumos à formação do ambiente de inovação

\begin{tabular}{|c|c|}
\hline Proxies & Características (1) \\
\hline $\begin{array}{l}\text { Fontes externas } \\
\text { de P\&D }\end{array}$ & $\begin{array}{l}2005 \text { - Aproximadamente } 88 \% \text { das empresas dos STs que implantaram } \\
\text { inovaçóes as fizeram em processo e de forma incremental. } \\
\text { Outras empresas e institutos (extrafirma) foram os principais } \\
\text { responsáveis pelo desenvolvimento, no caso do produto. } \\
2008 \text { - } \\
75,34 \% \text { das empresas implementaram inovações. } \\
37,11 \% \text { realizaram inovações em processos e de forma incremental, } \\
\text { aprimorando algo já existente. A inovação em processo foi atribuída } \\
\text { principalmente a outras empresas e institutos. } \\
\text { No caso do produto, o principal responsável pelas inovações foi a } \\
\text { própria empresa. }\end{array}$ \\
\hline Cooperação & $\begin{array}{l}2005 \text { - } 20 \% \text { dos processos foram realizados com outras empresas ou institutos } \\
\text { desenvolvidos. } \\
\mathbf{2 0 0 8} \text { - } 26 \% \text { dos processos foram realizados com outras empresas ou institutos, } \\
\text { indicando que esta prática tornou-se mais frequente no setor. }\end{array}$ \\
\hline $\begin{array}{l}\text { Fomento do } \\
\text { setor público }\end{array}$ & $\begin{array}{l}2005 \text { - } 10 \% \text { das empresas que realizaram P\&D receberam apoio do governo } \\
\text { para parcerias com universidades e institutos de pesquisa e aquisição } \\
\text { de máquinas. } \\
2008 \text { - } 26 \% \text { receberam apoio do governo. } \\
\text { Os recursos recebidos como incentivo fiscal foram assim distribuídos: } \\
4 \% \text { para P\&D; } 1 \% \text { foi captado pela Lei de Informática; } 5 \% \text { recebidos } \\
\text { como subvençóes econômicas; e } 10 \% \text { como apoioà compra de máquinas } \\
\text { e equipamentos. Esse aumento de } 160 \% \text { na captação de recursos sugere } \\
\text { que houve maior busca por financiamento governamental a P\&D e que } \\
\text { existe certa disponibilidade financeira para custear estes projetos. }\end{array}$ \\
\hline
\end{tabular}

7 Em janeiro de 2011, a Motorola dividiu-se oficialmente em duas companhias, a Motorola Mobility, focada em negócios com celulares, acessórios, tablets e decodificadores de TV; e Motorola Solutions, focada em negócios que incluem escâner de código de barras, redes sem fio e rádios intercomunicadores.

8 A sueca Ericsson (Telefonaktiebolaget L. M. Ericsson) e a Sony Corporation formaram, em 2001, uma joint venture para a produção de telefones celulares e soluções com tecnológica móvel. No início de 2012, a parceria foi desfeita com a aquisição dos 50\% do capital da Ericsson pela Sony, passando a se chamar Sony Mobile Communications. Além da Sony, a Ericsson possui parcerias com outras empresas como a LG. 
QUADRO 3

Insumos à formação do ambiente de inovação

\begin{tabular}{|c|c|}
\hline Proxies & Características (1) \\
\hline Educação & $\begin{array}{l}2005 \text { e } \\
2008 \text { - O total de pessoal das empresas, com formação superior, diretamente } \\
\text { ocupado com atividades de P\&D aumentou em 5\%, no período. } \\
\text { Nesse percentual houve uma queda de } 19 \% \text { de profissionais com } \\
\text { pós-graduação e } 36 \% \text { com ensino médio e um aumento de } 8 \% \text { no } \\
\text { número de graduados envolvidos com P\&D. }\end{array}$ \\
\hline $\begin{array}{l}\text { Outras } \\
\text { instituiçóes }\end{array}$ & $\begin{aligned} 2005 & -57,48 \% \text { consideraram de extrema importância as redes de informação } \\
& \text { informatizadas (2). } \\
& 54,66 \% \text { destacaram os fornecedores. } \\
& 32,34 \% \text { mencionaram os clientes. } \\
2008 \text { - } & \text { as empresas indicaram as redes de informação informatizadas }(84,65), \\
& \text { os fornecedores }(44,85 \%) \text {, os concorrentes }(32,23 \%) \text { e outras } \\
& \text { empresas do grupo }(30,25 \%) .\end{aligned}$ \\
\hline Treinamento & $\begin{array}{l}2005 \text { - } 51 \% \text { das empresas atribuíram alta importância ao treinamento. } \\
\text { Outros itens comparados ao treinamento: compra de máquinas e } \\
\text { equipamentos }(76 \%) \text {; aquisição de softwares }(58 \%) \text {; e utilização de } \\
\text { projetos industriais }(51 \%) \text {. } \\
2008 \text { - } 62 \% \text { afirmaram ser de extrema relevância o treinamento e qualificação } \\
\text { do pessoal, percentual inferior apenas à importância dada para } \\
\text { aquisição de novas máquinas e equipamentos }(74 \%) \text {. }\end{array}$ \\
\hline
\end{tabular}

Fonte: Elaboração dos autores a partir das Pintecs 2005 e 2008 (IBGE, 2007, 2010).

(1) As informaçōes expressas em valores percentuais foram retiradas das Pintecs 2005 e 2008 e no texto fez-se referência apenas ao ano da pesquisa. Os dados referem-se somente às empresas que implementaram inovaçóes no período abrangido pelas pesquisas (IBGE, 2007, 2010).

(2) Redes de informação informatizadas são constituídas por membros, elementos ou unidades que habilitam e promovem o acesso a informações, independentemente de seleção ou valoração dos dados repassados (IBGE, 2007).

A seguir, apresentam-se alguns detalhes adicionais sobre cada item incluído no Quadro 3.

Fontes externas de $P \& D$ - A procura por essas fontes foi incentivada pela Lei de Inovação (Lei n. 10.973/04) e favorecida pelas ações do Centro de Pesquisa e Desenvolvimento (CPqD). É fomentada, também, pela Lei Geral de Telecomunicaçōes (LGT), que ocasionou a migração dos investimentos em P\&D das operadoras para os fornecedores de máquinas e equipamentos.

Cooperação - É possível ocorrer entre empresas de setores ou segmentos distintos e também devido à migração dos investimentos em P\&D das operadoras para os for- 
necedores. Entre os atores deste mercado, a cooperação é incentivada e está prevista na Lei de Inovação (Capítulo 2), que trata do estímulo à construção de ambientes especializados e cooperativos de inovação.

Fomento do setor público - Este tem sido facilitado via Banco Nacional de Desenvolvimento Econômico e Social - BNDES, Fundo Nacional para o Desenvolvimento Científico e Tecnológico - FNDCT (CT-Info) e induzida pela LGT. Também foi incentivado pela Lei de Inovação (Cap. 4 - Do Estímulo a Inovação nas Empresas; Cap.6 - Dos Fundos de Investimento). São destinados os recursos de fomento dos Fundos Setoriais.

Educação - Formação de pessoal qualificado via expansão do ensino superior público (institutos federais de educação e universidades públicas pelo Reuni), com ênfase nos cursos de engenharia, e custeio do ensino superior particular (Prouni). O incentivo dado pela Lei de Inovação possibilita as instituições de ensino superior a se apropriarem de parte das receitas decorrentes de inovações realizadas em seus laboratórios. Isso acaba por incentivá-las a aumentarem suas pesquisas e a qualificarem seu pessoal.

Outras instituiçôes - A busca por apoio de outras instituições que possuam expertise necessária à atividade inovativa é incentivada pela Lei de Informática, que permite que gastos com recursos humanos diretos e indiretos, serviços técnicos e outros correlatos sejam enquadrados como dispêndios de P\&D. De certa maneira esta procura também é induzida pela LGT, uma vez que ocorreu migração dos investimentos em P\&D das operadoras para os fornecedores, havendo a necessidade de desenvolver novas competências nas organizaçōes (GALINA; PLONSKI, 2005). Isto é visível na comparação dos dados das Pintecs 2005 e 2008, no Quadro 3, apresentando nítido aumento da preferência pelos fornecedores como fonte de inovação.

Treinamento - A capacitação por meio de treinamentos é incentivada pela Lei de Informática, que permite que gastos com treinamento sejam enquadrados como dispêndios de P\&D. Também estão disponíveis recursos dos Fundos Setoriais que, em 2006, destinaram $\mathrm{R} \$ 159$ milhôes à área de fomento e $\mathrm{R} \$ 11$ milhões à capacitação e qualificação de recursos humanos de empresas com parcerias e interação com instituiçōes científicas e tecnológicas (MCT, 2011). 
Ao aprofundar a análise do AI deste setor, percebe-se que as empresas de STs ainda inovam de forma incremental, valendo-se principalmente de parceiros comerciais em detrimento das universidades e centros de pesquisa, como citado na caracterização da proxy fontes externas de P\&D e demais. Paralelamente, estas firmas têm aumentado suas joint ventures, com outras empresas do setor ou com institutos de pesquisa, além do efetivo com formação superior envolvido nos processos de P\&D.

As empresas do setor de STs aparentemente valem-se das diversas possibilidades de custeio oferecidas pelos instrumentos legais, pois apenas uma pequena parcela das empresas (1\%) fez uso do financiamento público direto e $26 \%$ delas receberam incentivos fiscais. Isso suscita um comportamento por parte das empresas do setor que buscam soluçôes particulares às suas demandas, prioritariamente por meio de financiamento próprio e depois de parceiros. O envolvimento com o poder público parece ser algo avesso ao comportamento destas firmas.

Diante destas informações, percebe-se que o Brasil procura, como afirmou Nascimento (2010), alcançar os países próximos da fronteira tecnológica da área de telecomunicaçôes, mas permanece longe de efetivamente aproximar-se dos países líderes nesta área. Há que se ressaltar, como visto no Quadro 3, que os esforços governamentais, mesmo que algumas vezes tardios ou insuficientes, no caso de recursos financeiros, têm sido feitos, ao menos, para que o setor de STs brasileiro diminua sua dependência tecnológica estrangeira de máquinas e equipamentos. Alguns dos pontos observados no Quadro 3 são ratificados por Dutra (2007, p. 16), ao enfatizar que:

[...] operadoras de serviços de telecomunicação adotam, no Brasil, estratégias de inovação defensivas na medida em que a convergência de serviços deve acontecer pela implantação de serviços incrementais derivados da plataforma tecnológica existente. Unânimes, todas querem a convergência, desde que sob seu comando.

Em seguida procurou-se verificar em que medida as características descritas por Marsili (2000) sobre o RT do setor de telecomunicaçôes em países economicamente desenvolvidos podem ser identificadas no caso brasileiro. Para tanto, foram utilizados basicamente dados das Pintecs 2005 e 2008 e a legislação aplicável. Os resultados são apresentados de forma sintética no Quadro 4, no intuito apenas de relacioná-los ao setor brasileiro com a taxonomia de Marsili (2001), e discutidos com mais detalhes posteriormente. 


\section{QUADRO 4}

Regime tecnológico do setor de serviços de telecomunicações brasileiro adaptado da taxonomia de Marsili (2001)

\begin{tabular}{|c|c|c|}
\hline $\begin{array}{l}\text { Perspectivas ou } \\
\text { dimensóes }\end{array}$ & $\begin{array}{c}\text { Intensidade } \\
\text { observada por } \\
\text { Marsili }\end{array}$ & $\begin{array}{l}\text { Intensidade observada no setor de } \\
\text { telecomunicaçôes no Brasil (1) }\end{array}$ \\
\hline $\begin{array}{l}\text { Oportunidade } \\
\text { tecnológica }\end{array}$ & Alta & $\begin{array}{l}\text { Alta - Tanto em produto quanto em processo existem } \\
\text { inúmeras oportunidades de apresentar um produto } \\
\text { ou serviço novo ao mercado. Como exemplo tem-se o } \\
\text { Serviço Móvel Pessoal (SMP), que passou a ser gênero } \\
\text { de primeira necessidade. }\end{array}$ \\
\hline $\begin{array}{l}\text { Barreiras } \\
\text { tecnológicas } \\
\text { à entrada em } \\
\text { conhecimen- } \\
\text { to/escala }\end{array}$ & $\begin{array}{l}\text { Alta } \\
\text { (conhecimento) }\end{array}$ & $\begin{array}{l}\text { Alta - As condições de mercado também exercem } \\
\text { forte influência para a não geração de conhecimento e } \\
\text { sim da incorporação das inovaçôes geradas por outras } \\
\text { empresas. }\end{array}$ \\
\hline $\begin{array}{l}\text { Persistência da } \\
\text { inovação }\end{array}$ & Alta & $\begin{array}{l}\text { Baixa - Esse item difere do de Marsili. O número de } \\
\text { empresas de STs que implementaram alguma inovação } \\
\text { caiu de } 19,76 \% \text { para } 7,89 \% \text {, entre } 2005 \text { e } 2008 \text {. En- } \\
\text { tretanto, aquelas que investem de forma contínua salta- } \\
\text { ram de } 77,06 \% \text { para } 99,56 \% \text { e o percentual de recur- } \\
\text { sos aportados nestas pesquisas passou de } 97,37 \% \text { para } \\
99,98 \% \text {. Em } 2005 \text { a quantia investida em P\&D pelo } \\
\text { setor representou } 4,3 \% \text { do total gasto em P\&D no país, } \\
\text { aumentando para } 7,9 \% \text { em } 2008 \text {. }\end{array}$ \\
\hline $\begin{array}{l}\text { Diversidade entre } \\
\text { empresas }\end{array}$ & Baixa & $\begin{array}{l}\text { Baixa-AsempresasdosetordeSTsbrasileiroapresentam } \\
\text { inovações incrementais que são rapidamente copiadas } \\
\text { ou incorporadas pelas concorrentes, devido ao alto } \\
\text { spillover, à padronização das tecnologias determinada } \\
\text { pela ITU e à regulamentação do setor pela Anatel } \\
\text { (REZENDE, 2011; DUTRA, 2007). }\end{array}$ \\
\hline $\begin{array}{l}\text { Diferenciação } \\
\text { das bases de } \\
\text { conhecimento } \\
\text { (principais } \\
\text { direçóes) }\end{array}$ & Baixa & $\begin{array}{l}\text { Baixa - Em } 2008 \text {, entre as fontes internas, identificou- } \\
\text { se uma forte relação com o conhecimento obtido em } \\
\text { outras áreas da empresa. Isso possivelmente deve- } \\
\text { se à pouca quantidade de empresas que possuem } \\
\text { departamentos internos de P\&D. Já as fontes } \\
\text { externas de conhecimento, em ordem decrescente } \\
\text { de importância, são: outra empresa do grupo, } \\
\text { fornecedores, clientes e consumidores. Em 2005, } \\
\text { aproximadamente } 45,7 \% \text { das empresas indicaram } \\
\text { como fonte de informações os centros de capacitação } \\
\text { profissional e assistência técnica no Brasil. Em 2008, } \\
\text { predominaram essas mesmas fontes de informação, } \\
\text { para inovação das firmas de STs; no entanto, houve } \\
\text { maior ocorrência de as informaçōes virem dos } \\
\text { concorrentes em lugar dos fornecedores. }\end{array}$ \\
\hline
\end{tabular}

(continua) 
QUADRO 4

Regime tecnológico do setor de serviços de telecomunicaçóes brasileiro adaptado da taxonomia de Marsili (2001)

\begin{tabular}{|c|c|c|}
\hline $\begin{array}{l}\text { Perspectivas ou } \\
\text { dimensōes }\end{array}$ & $\begin{array}{c}\text { Intensidade } \\
\text { observada por } \\
\text { Marsili }\end{array}$ & $\begin{array}{l}\text { (continuaçăo) } \\
\text { Intensidade observada no setor de } \\
\text { telecomunicaçôes no Brasil (1) }\end{array}$ \\
\hline $\begin{array}{l}\text { Fontes externas de } \\
\text { conhecimento }\end{array}$ & $\begin{array}{l}\text { Instituições } \\
\text { públicas } \\
\text { e joint ventures }\end{array}$ & $\begin{array}{l}\text { As empresas de STs, em 2005, informaram serem } \\
\text { importantes as parcerias com os fornecedores }(72,4 \%) \text {. } \\
\text { Contudo, entre seus parceiros encontram-se, além } \\
\text { dos fornecedores nacionais (60,3\%), os clientes e } \\
\text { consumidores }(34,5 \%) \text { e demais empresas do mesmo } \\
\text { grupo }(32,8 \%) \text { Em 2008, } 87,13 \% \text { consideravam } \\
\text { altamente relevante a cooperação com empresas } \\
\text { fornecedoras, em sua maioria nacionais, } 37,88 \% \text { com } \\
\text { outras empresas do mesmo grupo, seja no Brasil, seja no } \\
\text { exterior, e, } 33,83 \% \text { com os institutos de testes, ensaios e } \\
\text { certificaçóes, principalmente nacionais. }\end{array}$ \\
\hline $\begin{array}{l}\text { Ligaçóes com } \\
\text { a pesquisa } \\
\text { acadêmica } \\
\text { (campos de } \\
\text { conhecimento) }\end{array}$ & $\begin{array}{l}\text { Forte e direto, } \\
\text { principalmente } \\
\text { campos de } \\
\text { conhecimento não } \\
\text { pervasivos (2) }\end{array}$ & $\begin{array}{l}\text { Fraco e direto - Apenas } 30 \% \text { das empresas que ino- } \\
\text { varam no setor de telecomunicaçóes, em } 2005 \text {, obtive- } \\
\text { ram conhecimento das universidades e institutos de } \\
\text { pesquisa. Deste percentual, somente } 50 \% \text { decorreram } \\
\text { de atividades de P\&D ou ensaios para testes de produto; } \\
\text { a outra metade resultou de demais atividades de coope- } \\
\text { ração. Em } 2008 \text {, verificou-se que os institutos de pes- } \\
\text { quisa foram responsáveis por } 41,1 \% \text { do conhecimento } \\
\text { e as universidades por } 39 \% \text {. Isso evidencia que a ligação } \\
\text { entre as empresas do setor de telecomunicações e a pes- } \\
\text { quisa acadêmica ainda não atingiu o grau de maturidade } \\
\text { adequado, se comparada com outras fontes de conheci- } \\
\text { mento informadas (como fornecedores). }\end{array}$ \\
\hline $\begin{array}{l}\text { Natureza da } \\
\text { inovação }\end{array}$ & Serviço (3) & $\begin{array}{l}\text { Por se tratar de um serviço de base tecnológica, a } \\
\text { inovação é tanto de produto como de processo, uma } \\
\text { vez que necessita de um equipamento para ser prestado. } \\
\text { Contudo, em } 2008 \text {, dadas as características do mercado } \\
\text { brasileiro e por ser esta uma análise do setor de serviços } \\
\text { em telecomunicaçôes, considerou-se a existência apenas } \\
\text { de inovação em processo. Somente } 8,23 \% \text { do total das } \\
\text { empresas do setor de serviços implementaram inovaçôes. } \\
\text { Destas, } 7,65 \% \text { implementaram processos inovadores } \\
\text { apenas para o setor nacional e } 33 \% \text { delas apresentaram } \\
\text { processos inovadores em termos mundiais. }\end{array}$ \\
\hline
\end{tabular}

Fonte: Elaboração dos autores a partir das Pintecs 2005 e 2008 (IBGE, 2007, 2010).

(1) As informaçōes expressas em valores percentuais foram retiradas das Pintecs 2005 e 2008 e no texto fez-se referência apenas ao ano da pesquisa (IBGE, 2007, 2010). Tais informaçōes juntamente com a literatura citada no quadro subsidiaram sua elaboração. (2) Trata-se de um anglicismo (pervasiveness, no original). Adjetivo que denota a qualidade ou propriedade de se difundir, de se espalhar, de permear.

(3) Para este estudo considerou-se, em vez de produto, a inovação no serviço. Segundo o Manual de Oslo, "toda a inovação que envolva características novas ou substancialmente melhoradas do serviço oferecido aos consumidores, trata-se de uma inovação de produto" (OCDE, 2005, p. 64). 
Cada um dos itens apresentados no Quadro 4 é discutido a seguir.

Oportunidade tecnológica - É propiciada pela percepção mais favorável dos consumidores do SMP. Isso é resultado de investimentos em melhorias na qualidade dos serviços, envolvendo equipamentos, qualidade e segurança de conexão de dados e voz, bem como em pessoal capacitado para atuar diretamente com o consumidor, o que, segundo Rezende (2011), influencia diretamente na competitividade das operadoras. A implementação contínua de melhorias nos STs é perceptível, diante das inovações ocorridas nas TICs, via convergência de plataformas, ou integração de equipamentos de telecomunicações, mas tais melhorias também ocorrem para atender às exigências e às metas de expansão e qualidade impostas pela Anatel para garantir o cumprimento do art.20 da LGT (BRASIL, 1997). As empresas de STs atendem, ainda, às premissas de mutação, seleção e transmissão de tecnologia dentro do setor. Mesmo indicando a ocorrência de alta oportunidade tecnológica, essas firmas não se distanciam tecnologicamente umas das outras, fazendo isso apenas quando há um estímulo externo. Ou, como disse Dutra (2007), elas acabam implementando serviços incrementais derivados de uma plataforma que já utilizam. No caso dos STs brasileiros, antes de entrarem no mercado, as inovações devem ser homologadas pela Anatel, sendo que, após serem disponibilizadas para o usuário, são rapidamente copiadas pelas concorrentes, o que dá à empresa inovadora pouca vantagem em relação às concorrentes (REZENDE, 2011).

Barreiras tecnológicas à entrada em conhecimentolescala - A tecnologia envolvida é relativamente de fácil incorporação, o que acarreta, no médio prazo, a padronização dos serviços prestados, tornando a tecnologia neste serviço "off-the-shelf", conforme definiu Tether (2004). A barreira à entrada se dá pela capacidade de investimento das operadoras. Outro ponto que eleva a barreira a novos entrantes encontra-se nas economias de escala relacionadas a prestação do serviço, compras, P\&D, rede de vendas e serviços agregados e custeio da operação. Isso favorece o fortalecimento da marca, que está diretamente relacionada com toda a cadeia de valor dos STs (TETHER, 2004).

Persistência à inovação - No Brasil ela é baixa. Analisando os dados das empresas dos STs nas Pintecs 2005 e 2008 para tratar esta dimensão, suscita-se que houve uma "pré-disposição natural" entre elas, fazendo com que um número menor de empresas investisse e produzisse em 2008 mais do que o conjunto de firmas ob- 
servado em 2005, levando a crer que algumas estejam se especializando na geração de inovaçôes para STs.

Diversidade entre empresas - Seguindo o padrão mundial, é baixa no país. Segundo Prieger (2002), a diversidade exercida de forma excessiva acaba sendo contrária ao crescimento e ao desenvolvimento tecnológico do setor de STs. No caso do mercado brasileiro, prejudica também a estrutura de fomento à inovação.

Diferenciação das bases de conhecimento - Da mesma forma que em outros países, é baixa no Brasil. Quando questionados sobre a localização da fonte de informações empregadas para inovar, os empresários afirmaram que elas vinham principalmente dos clientes e consumidores, fornecedores e concorrentes. Redes de informação informatizadas e centros de capacitação profissional também surgem como grandes contribuintes de conhecimento para inovação. Mesmo havendo uma sutil mudança nas bases de conhecimento, estas diferenciaçôes são definidas como baixas, pois se mantêm concentradas em poucas bases. Ou seja, não houve ampliação das fontes de geração de conhecimento, no período analisado. Aparentemente ocorre a incorporação, após adequações, das informações que são recebidas como feedbacks.

Fontes externas de conhecimento - A parceria com universidades e instituições de pesquisa ou demais instituições públicas de geração de conhecimento é definida como pouco relevante para o setor de STs nas duas pesquisas. Houve parcerias, mas não foi possível determinar sua natureza, segundo dados da Pintecs 2005 e 2008, não podendo, então, afirmar que constituem uma joint venture. Sabe-se, no entanto, que, mesmo não sendo consideradas pelos players do setor como fontes externas relevantes de conhecimento, as instituiçōes públicas e as joint ventures têm se tornado, gradualmente, fontes mais corriqueiras de conhecimento para as empresas do setor, conforme demonstram as Pintecs de 2005 e 2008.

Ligaçôes com a pesquisa acadêmica - Ao contrário do que ocorre fora, ela é fraca no Brasil. O setor vale-se principalmente da pesquisa aplicada, mantendo estreito relacionamento com pesquisas desenvolvidas nas áreas de engenharia de materiais, elétrica e eletrônica e de telecomunicações, além da ciência da computação. Como afirmou Dutra (2007), as empresas do setor no Brasil adotam estratégias defensivas e optam pela implantação de serviços incrementais. 
Natureza da inovação - serviço - Retomando Dutra (2007), as empresas que atuam nos STs optam pela implantação de serviços incrementais derivados da plataforma tecnológica existente. No caso da telefonia móvel, particularmente, utiliza-se a plataforma GSM (Global System for Mobile Communications), que é mais difundida entre os fabricantes de equipamentos e requer investimentos menores para fornecer um incremento tecnológico (PORTAL DA TELEFONIA, 2011).

As empresas de STs que tiveram inovação em processo ou produto reduziram o desenvolvimento interno de P\&D, passando de 45,2\% para 14,91\%, entre 2005 e 2008 (IBGE, 2007, 2010). Suscita-se que isso deva-se a uma oligopolização dos STs, em que apenas grandes empresas do setor desenvolvem efetivamente P\&D internamente, corroborando as afirmações feitas por Dutra (2007). Tal constatação também condiz com o proposto pela taxonomia de Marsili (2001) e de Pavitt (1984), pois, em se tratando de um setor baseado em ciência, era esperado um percentual maior de inovação gerada pelos players. No entanto, Gallouj e Windrum (2009) relatam que uma das liçôes mais importantes que o estudo de inovação lhes ensinou é que as taxas de inovação são desiguais, de modo que toda a ação acontece nas caudas da distribuição populacional, com algumas poucas empresas de grande sucesso e elevado desempenho.

Outro ponto a ser destacado refere-se aos impactos proporcionados pela inovação que as empresas consideraram mais importantes (Gráfico 1). Observa-se que, entre 2005 e 2008, a inovação proporcionou, em termos percentuais, às firmas de STs manter, ampliar e abrir novos mercados, além de aumentar a capacidade produtiva. Paralelamente, no mesmo período, gerou-se uma redução na melhoria da qualidade do produto e na flexibilização da produção.

É importante ressaltar que, nas duas pesquisas, as empresas de STs investiram, principalmente, em máquinas e equipamentos e em softwares. Em 2005, a atividade de treinamento não era considerada uma fonte geradora de inovação, passando a ter mais destaque em 2008. Isso sugere maior preocupação com a qualificação de pessoal e, consequentemente, pode futuramente afetar a qualidade do serviço prestado por estas empresas, mesmo que esta relação não seja atualmente verificada no quesito "melhoria da qualidade do produto". A disponibilidade de tecnologia proporciona a inserção de novos players, possibilitando uma ampla diversificação dos serviços na expectativa de criar um diferencial. As empresas do setor de STs tendem, assim, a inovar com foco no cliente e na capacidade de agregar valor ao seu serviço (SANTA RITA; SBRAGIA, 2006, FRANSMAN, 2003). 


\section{GRÁFICO 1}

Impactos proporcionados pela inovação considerados mais importantes pelas empresas de serviços de telecomunicações

Brasil - 2005-2008

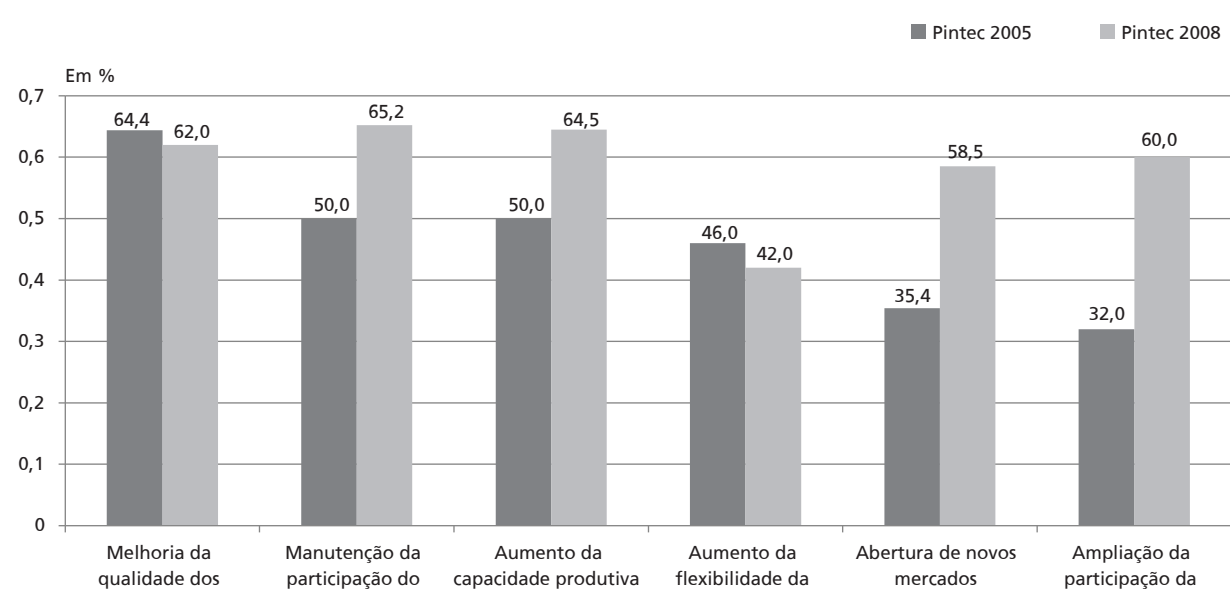

Fonte: Pintec 2005 e 2008 (IBGE, 2007, 2010).

Nota: Valores calculados com base nas empresas do setor de STs que inovaram em processos ou produtos.

Valores absolutos: 180 empresas - Pintec 2005; 334 empresas Pintec 2008.

Para enriquecer o estudo, fez-se, também, uma análise das características dos STs brasileiro, com base naquelas definidas no RT, por Malerba e Orsenigo (1993):

oportunidade - sofre certa restrição, uma vez que todos os segmentos do setor de telecomunicaçōes brasileiro foram delimitados por concessão e por regiōes de atuação até a edição da nova LGT e a estruturação da rede de transmissão brasileira. Existe, ainda, o Conselho Administrativo de Defesa Econômica - Cade, que intervém sempre que há entendimento de que uma empresa esteja infringindo a ordem econômica (Lei n. 8.884/94). Isso limita diretamente a expansão das áreas de atuação das firmas;

apropriabilidade - observou-se, com base na Pintec 2005, que as empresas do setor de STs brasileiro valem-se principalmente das marcas, em detrimento das patentes, como método de proteção "escrito" de suas inovações e utilizam o segredo industrial como estratégia para resguardá-las e garantir a apropriabilidade de suas inovações. Apenas 2,7\% das firmas que inovaram solicitaram o registro de patente e somente $1,6 \%$ ainda possuem uma patente em vigor. Em 2008 houve crescimento em valores absolutos de $43,4 \%$ da opção do setor por marcas, mantendo a preferência em relação a patentes (IBGE, 2007, 2010); 
cumulatividade - a Lei de Propriedade Intelectual ${ }^{1}$ foi fundamental para estimular a inovação, ao garantir a apropriação dos lucros vindos do direito de propriedade ao detentor desta patente. Contudo, mesmo existindo essa regulamentação, a cumulatividade é resultante muito mais de um comportamento das empresas em relação à valorização de seus funcionários e da manutenção de rotinas que permitam a acumulação e transferência de conhecimento quando necessária, do que por uma ação externa propriamente. Certo mesmo é que, se não houver disponibilidade financeira, a manutenção do know-how das organizações está comprometida;

a tecnologia de prateleira (off-the-shelf) possibilita a inserção de novos players, que, por sua vez, podem proporcionar uma gama de serviços com diferencial em relação aos demais. As empresas do setor de STs tendem, assim, a inovar com foco no cliente e na capacidade de agregar valor ao seu serviço (SANTA RITA; SBRAGIA, 2006; FRANSMAN, 2003). Daí a base de conhecimento, o know-how e a cumulatividade tornarem-se fatores que diferenciarão os players do setor de STs, pois a existência destas características deve-se às rotinas da empresa inovadora. Ou seja, há um círculo virtuoso, no qual as empresas, ao vislumbrarem uma oportunidade de inovar ou diferenciar seus serviços, o fazem. A existência de sinergia entre oportunidade, apropriabilidade e cumulatividade faz com que a base do conhecimento retroalimente o círculo, beneficiando tanto as empresa quanto aqueles que utilizam os STs, seja no Brasil ou no exterior.

O estudo de Santa Rita e Sbragia (2006) demonstra que as empresas vinculadas ao setor de STs brasileiro apresentam forte dependência dos recursos oriundos da Lei de Informática, sem os quais ficam desestimuladas a gerar inovaçôes intrafirma, mesmo que mantenham um processo contínuo de inovações incrementais, como mencionado por Dutra (2007). Na contramão deste processo, as operadoras brasileiras devem lidar com a busca por lucros praticando preços competitivos (baixos) e acessíveis, principalmente para as classes C, D e E, que, devido ao aumento de suas rendas, são os grandes nichos a serem explorados por elas e demais segmentos dos STs. Com o aumento da renda também elevou-se o nível de exigência por qualidade e preço daquilo que consomem, o que, por sua vez, alimenta o processo de inovação das empresas de STs. Este é um fato também descrito por Fransman (2007), ao afirmar que no final da década de 1990 houve, no mercado internacional, uma

9 A Lei de Propriedade Industrial Brasileira (n. 9.279/96) está em conformidade com a legislação internacional de propriedade intelectual em vigor. 
mudança de comportamento das firmas de STs, iniciado com a japonesa DoCoMo, ${ }^{10}$ ao focar como mercado consumidor o público jovem, e que caracteriza também a instituição do que vem a ser chamado no Brasil de "planos" ou "pacotes" de serviços. Estes "planos", por sua vez, resultam da evolução na prestação de serviços e constituem uma inovação em produto, conforme o Manual de Oslo (OCDE, 2005 ${ }^{11}$ ).

Todos estes pontos retratam a estrutura organizacional, legal e mercadológica deste setor, que ainda requer soluções para vários problemas. Mas ainda assim, a partir desta análise, foi possível estabelecer uma separação desta estrutura em dois grupos distintos, classificados segundo sua capacidade indutora à inovação:

estrutura regulamentadora -engloba elementos que delimitam a atuação, norteiam e definem atividades e agentes. Compreende basicamente as leis específicas para o setor de telecomunicaçôes, que podem ser vistas segundo o olhar evolucionário como sendo as que instituem as macrorrotinas do setor e das empresas que o compóem. É composta ainda pelos agentes reguladores dos STs, tais como MC, Anatel, Cade, etc.;

estrutura dinamizadora - composta por elementos que favorecem o surgimento de inovações e dão sustentação durante todo o seu desenvolvimento e comercialização, como é o caso das Leis de Propriedade Intelectual e de Informática. Associado a isso, existem fontes de fomento à inovação e nacionalização de produtos, geridas por diversos agentes governamentais, como o Conselho Nacional de Desenvolvimento Científico e Tecnológico (CNPq) e a Financiadora de Estudos e Projetos (Finep), entre outros.

\section{Conclusões}

A estrutura organizacional, legal e mercadológica brasileira, considerada dinamizadora do processo de inovação tecnológica, apresenta alguns aspectos compatíveis com os pressupostos evolucionários. No entanto, o apoio específico aos STs classificado como estrutura regulamentadora, por si só, não estimula ou sustenta, no longo prazo, um ambiente de inovação e um regime tecnológico dinâmicos, como é característico dos setores baseados em ciência. Logo, essa estrutura é necessária, mas não suficiente para estimular o setor a promover inovações de maneira contínua.

10 A DoCoMo começou a ofertar o serviço de Internet móvel (i-mode) com um segmento de consumo específico já definido. Planejou-se até a questão do conteúdo e aplicaçôes que este segmento de consumidores queria, com o preço destes serviços e as tecnologias que seriam necessários para entregá-los (FRANSMAN, 2003).

11 Vide chamada (3) no Quadro 4. 
Mediante a proposta feita neste trabalho, de verificar se as características do setor de STs brasileiro se ajustam às observadas no RT internacional, pode-se dizer que o RT brasileiro apresenta similaridades com aquele constatado por Marsili (2001) para a indústria em países desenvolvidos. Contudo, são verificadas divergências: na persistência de baixo nível de inovação no Brasil, uma vez que a maioria das empresas de STs investe em P\&D ocasionalmente; nas fontes externas de conhecimento, dado que as firmas brasileiras do setor priorizam os fornecedores e clientes ou consumidores em detrimento das parcerias com instituições públicas de pesquisa e joint ventures, para geração de novos produtos ou serviços; e na relação com a pesquisa acadêmica, considerada baixa se comparada às demais fontes de conhecimento. Estas características sugerem a forte influência dos fornecedores na incorporação de inovações, configurando-se um setor supplier dominated.

Diante das características observadas no RT brasileiro, percebe-se que a relação entre indústria e fontes de conhecimento ainda não é madura o suficiente. A consequência disto é que a presença do Estado como agente regulador e financiador intensivo de P\&D ainda se faz necessária para acompanhar o dinamismo, em nível mundial, dos STs.

Já o AI brasileiro para os STs tem sido moldado por meio de uma estrutura e de leis que não são direcionadas a setores específicos, mas que acabam por complementar a legislação de telecomunicações e impulsionar a geração de novos conhecimentos e inovaçōes no setor, mesmo que estes sejam incrementais.

Em suma, até o momento o Estado não foi capaz de construir uma estrutura dinamizadora do processo de inovação tecnológica eficiente, específica para os STs. Isso é, de certa forma, compreensível, uma vez que os investimentos na reestruturação do sistema de telecomunicações e na formação de tecnologias locais foram negligenciados pela estagnação do setor, no período em que esteve sob o controle do Estado até sua privatização, em 1995.

Apesar disso, pode-se dizer que o Estado brasileiro criou a estrutura legal básica, embora superficial, no intuito de promover um AI e favorecer o surgimento de um RT pujante. Entretanto, a legislação brasileira não é dinâmica a ponto de seguir os progressos ocorridos nos setores baseados em tecnologia, tornando-se necessária a criação de instrumentos que acompanhem tais avanços. Setores como o de telecomunicações, que são eminentemente dinâmicos nos Estados Unidos e na Europa, apresentam um desempenho inferior no mercado brasileiro, devido à estrutura “engessada” observada aqui (REZENDE, 2011; PRIEGER, 2000). 
Esforços na redução do tempo para obtenção de patentes, na homologação de novas tecnologias de transmissão junto à Anatel e na supressão de qualquer tipo de problema que dificulta o processo inovativo devem ser feitos urgentemente, para que o país possa acompanhar de maneira efetiva a evolução do mercado mundial. Além disso, mecanismos simplificados de acesso aos fundos disponíveis ao setor devem ser implementados, como forma de estimular os inventores a buscarem, junto à União, os recursos necessários para seus projetos.

Deve-se ressaltar, por fim, que o modelo de Marsili (2001) utilizado não é totalmente adequado para se compreender perfeitamente o setor de serviços, o que demonstra a necessidade de adaptaçôes para atender de forma satisfatória ao setor de serviços, principalmente se forem observados os países emergentes.

Contudo, esse modelo permitiu que o presente trabalho contribuísse para a literatura sobre o assunto com a construção de uma classificação simples, mas bastante aplicável à realidade brasileira para mensurar a efetividade da estrutura disponibilizada pelo Estado para incentivar a pesquisa, desenvolvimento e inovação em qualquer setor econômico.

\section{Referências bibliográficas}

ANATEL - Agencia Nacional de Telecomunicações. Disponível em: <http://www.anatel. gov.br>. Acesso em: 16 jul. 2012.

BRASIL. Decreto n. 6.654, de 20 de novembro de 2008. Disponível em: <http://www.planalto.gov.br/ccivil_03/_Ato2007-2010/2008/Decreto/D6654.htm>. Acesso em: 30 out. 2010.

. Lei n. 11.196, de 21 de novembro de 2005. Disponível em: <http://www. planalto.gov.br/ccivil_03/_ato2004-2006/2005/lei/L11196.htm>. Acesso em: 30 out. 2010.

Lei n. 10.973, de 2 de dezembro de 2004. Disponível em: <http://www.planalto.gov.br/ccivil_03/_ato2004-2006/2004/lei/110.973.htm>. Acesso em: 30 out. 2010.

. Decreto n. 2.534, de 2 de abril de 1998. Disponível em: <http://www.planalto. gov.br/ccivil_03/decreto/d2534.htm>. Acesso em: 30 out. 2010.

Lei n. 9.472, de 16 de julho de 1997. Disponível em: <http://www.planalto. gov.br/ccivil/leis/L9472.htm>. Acesso em: 29 ago. 2010.

. Emenda Constitucional n. 8, de 15 de agosto de 1995. Disponível em: <http:// www.planalto.gov.br/ccivil_03/constituicao/Emendas/Emc/emc08.htm>. Acesso em: 14 jun. 2012. 
Regime tecnológico e ambiente de inovação para o setor de serviços de telecomunicação

CNAE - Classificação Nacional de Atividades Econômicas. Disponível em: <http://www. cnae.ibge.gov.br/>. Acesso em: 7 out. 2011.

DROEGE, H.; HILDEBRAND, D.; FORCADA, M. H. Innovation in services: present findings, and future pathways. Journal of Service Management, v. 20, n. 2, p. 131-155, 2009.

DOSI, G. Institutions and markets in a dynamic world. The Manchester School of Economic \& Social Studies, v. 56, n. 2. p. 119-46, jun. 1988a.

Sources, produces and microeconomic effects of inovation. Journal of Economic Literature, v. 26, n. 3. p.1120-171, set. 1988 b.

DE NEGRI, F.; RIBEIRO, L. C. Tendências tecnológicas mundiais em telecomunicações. Radar - Tecnologia, Produção e Comércio Exterior, n. 10, p.7-12, out. 2010.

DUTRA, L. S. Inovação na telecomunicação: a convergência de serviços. Inovação Uniemp, v. 3, n. 6, dez.2007. Disponível em: <http://inovacao.scielo.br/scielo.php?script=sci arttext\&pid=S1808-23942007000600008\&lng=pt\&nrm=iso>. Acesso em: 20 fev. 2013.

FRANSMAN, M. Innovation in the new ICT ecosystem. Communications \& Strategies, n. 68, $4^{\text {th }}$ Quarter. p. 89-110, 2007.

Knowledge and Industry Evolution: the mobile communications industry evolved largely by getting things wrong. In: DRUID Summer Conference 2003 on creating, sharing and transferring knowledge. Copenhagen, June, 2003.

FREITAS, F. H. As telecomunicações no Brasil e os desafios da regulação da concorrência. In: VII Congresso Internacional del CLAD sobre la reforma del estado y de la administración pública. Lisboa, 2002. Disponível em: <http://unpan1.un.org/intradoc/groups/public/ documents/clad/clad0044310.pdf>. Acesso em: 05 ago. 2010.

GADREY, J.; GALLOUJ, F.; WEINSTEIN, O. New modes of innovation: how services benefit industry. International Journal of Service Industry Management, v. 6, n. 3, p. 4-16, 1995.

GALINA, S. V. R.; PLONSKI, G. A. Inovação no setor de telecomunicações no Brasil: uma análise do comportamento empresarial. Revista Brasileira de Inovação - RBI, v. 4, n. 1, p. 129-155, 2005.

GALINA, S. V. R; PLONSKI, G. A. Desenvolvimento global de produtos no setor de telecomunicações - uma taxonomia para a participação brasileira. In: $2^{\circ}$ Congresso Brasileiro de Gestão de Desenvolvimento de Produtos. Anais... São Carlos: CBGDP, 2000.

GALLOUJ, F; WINDRUM, P. Services and services innovation. Journal of Evolutionary Economics, n. 19, p. 141-148, 2009. 
GUIDOLIN, S. M.; MARTINELLI, O. Regimes tecnológicos da indústria brasileira: uma contribuição para a análise empírica. In: 36º Encontro Nacional de Economia. Anais... Salvador: Anpec, 2008.

IBGE - Instituto Brasileiro de Geografia e Estatística. Pesquisa de Inovação Tecnológica PINTEC 2008. Rio de Janeiro: IBGE, 2010.

. Pesquisa Anual de Serviços. Rio de Janeiro: IBGE, 2008.

2007.

. Pesquisa de Inovação Tecnológica 2005 - PINTEC 2005. Rio de Janeiro: IBGE,

IUT - International Telecommunication Union. Disponível em: <http://www.itu.int/en/ Pages/default.aspx>. Acesso em: 10 jul. 2011.

KUBOTA, L. C. A inovação tecnológica das firmas de serviços no Brasil. In: DE NEGRI, J. A.; KUBOTA, L. C. (Orgs.). Estrutura e dinâmica do setor de serviços no Brasil. Brasília: Ipea, 2006.

MALACHIAS, C. S.; MEIRELLES, D. S. Regime tecnológico, ambiente de inovação e desempenho empresarial no setor de serviços: um estudo exploratório das empresas de tecnologia da informação. RAI-Revista de Administração e Inovação, v. 6, n. 2, p. 58-80, 2009.

MALERBA, F.; ORSENIGO, L. Technological regimes and firm behavior. Industrial o. Corporate Change, v. 2, n. 1, p. 45-72, 1993.

MARSILI, O. The anatomy and evolution of industries: technological change and industrial dynamics. Northampton: Edward Elgar Publishing Inc., 2001.

MC - Ministério das Comunicações. Disponível em: <www.mc.gov.br>. Acesso em: 6 jun. 2012.

MCT - Ministério da Ciência e Tecnologia. Disponível em: <www.mct.gov.br>. Acesso em: 7 out. 2011 .

MEIRELLES, D. S. O conceito de serviço. Revista de Economia Politica, v. 26, n. 1, p. 119-136, jan./mar. 2006.

MELO, M. C. S. A dinâmica da inovação no setor de telecomunicaçōes: uma análise a partir de dados da Pintec. FACEF Pesquisa, v. 12, n. 3, p. 349-364, 2009.

MILES, I. Services in the new industrial economy. Futures, v. 25, n. 6, p.653-672, 1993.

MIOZZO, M.; SOETE, L. Internationalization of services: a technological perspective. Technological Forecasting and Social Change, v. 67, p.159-185, 2001.

NASCIMENTO, P. A. M. Capacitações científicas do Brasil em telecomunicaçôes: o que se pode depreender da evolução recente da produção de artigos na área? Radar - Tecnologia, Produção e Comércio Exterior, n. 10, p. 13-24, out. 2010. 
Regime tecnológico e ambiente de inovação para o setor de serviços de telecomunicação

NELSON, R. R.; WINTER, S. G. An evolutionary theory of economic change. Cambridge, Massachusetts: Harvard University, 1982.

OCDE - Organização para a Cooperação e Desenvolvimento Econômico. Manual de Oslo. 3. ed. Brasília: Finep, 2005.

PAVITT, K. Sectorial patterns of technical change: towards a taxonomy and a theory. Research Policy, n. 13,pp. 343-373, 1984.

PORTAL DA TELEFONIA. Disponível em: <http://ensino.univates.br/ -tcnpaulo/telefoniacelular5.html>. Acesso em: 30 maio 2011.

PRIEGER, J. E. Regulation, innovation, and the introduction of new telecommunications services. The Review of Economic and Statistics, v. 84, n. 4, p. 704-715, 2002.

REDETEC - Rede de Tecnologia do Rio de Janeiro. Como criar um ambiente de inovação nas empresas. Rio de Janeiro: Redetec, 2008.

REZENDE, A. A. de. Aplicação de um modelo evolucionário para o segmento brasileiro de telefonia móvel. Dissertação (Mestrado em Economia). Viçosa, Universidade Federal de Viçosa, 2011.

SANTA RITA, L. P.; SBRAGIA, R. Inovação em serviços como condicionante da competitividade na telefonia móvel. Revista Cientifica Ciências Administrativas, v. 12, n. 1, p. 83-97, ago. 2006.

SILVA, A. M.; DE NEGRI, J. A. de; KUBOTA, L. C. Estrutura e dinâmica do setor de serviços no Brasil. In: DE NEGRI, J. A. de; KUBOTA, L. C. (Orgs.). Estrutura e dinâmica do setor de serviços no Brasil. Brasília: Ipea, 2006, p.15-33.

SUNDBO, J.; GALLOUJ, F. Innovation in services. Oslo: Step Group, 1998 (SI4S Synthesis Paper, S2).

TEIXEIRA, R.; LACERDA, D. P.; HEXSEL, A.; CASTAGNO JUNIOR, R. Fatores determinantes da competitividade na indústria de telecomunicaçôes e repercussōes para a estratégia. Revista de Administração e Contabilidade da Unisinos - BASE, v. 2, n. 1, p. 1526, jan.-abr. 2005.

TETHER, B. Do services innovative (differently). Manchester: CRIC, Nov. 2004 (CRIC Discussion Paper, n. 66).

TIDD, J.; BESSANT, J.; PAVITT, K. Integrating technological, market and organisational change. Chichester: John Wiley and Sons Ltd., 2001. 